\title{
A implicación da comunidade na mellora da convivencia escolar: o procedemento conciliador
}

\section{The implication of the community in the improvement of the school communal life: The conciliatory procedure}

\author{
Emilio J. Veiga*, Eduardo Rodríguez-Machado** \\ *Universidad de Santiago de Compostela, **Universidad Internacional de la Rioja
}

\begin{abstract}
Resumen
A recente publicación do D. 8/2015 do 8 de xaneiro, polo que se desenvolve a Lei $4 / 2011$, do 30 de xuño, de convivencia e participación da comunidade educativa en materia de convivencia escolar.

Así pois queremos destacar unha das ferramentas básicas que debemos desenvolver hoxe en día na maioría de centros educativos. Son os procedementos conciliadores instrumentos que pretenden favorecer a implicación e o compromiso do alumno ou alumna corrixido/a e da súa familia no caso de outras medidas preventivas aplicadas con anterioridade non teña sortido o efecto buscado.
\end{abstract}

Palabras claves: Educación en valores, cidadanía, comunidade educativa, competencias, convivencia.

\section{Abstract}

The recent publication of the D. 8/2015 of the 8th of January, for which the Law 4/2011, of the 30th of June, of communal life and participation of the educational community on the subject of school communal life, is developed.

So we want to send one of the basic tools that we have to unwrap nowadays in the majority of educational centers. They are the conciliatory procedures instruments that intend to favor the implication and the commitment of the pupil or pupil corrected/the and of his family in the event of other applied preventive measures with precedence the effect looked for does not have sortido.

Keywords: Education in values, citizenship, educational community, competences, communal life.

\section{Introducción}

Estamos nun momento social onde cada vez máis recaen sobre a institución escolar tarefas que tradicionalmente se situaban noutros niveis do entramado educativo. Así pois cada vez máis faise preciso poñer en xogo todas as ferramentas didactico-curriculares que dende os centros educativos poidamos desenvolver no senso de que o objetivo fundamental da escola que non debe ser outro que o de formar cidadáns intregrais e dicir abordando as cinco grandes capacidades do ser humano: cognitivas, cognitivas, motrices, de equilibrio persoal, de relación interpersoal e de inserción social, así como as Competencias Clave para a vida que se determinan nos escritos internacionais da OCDE (DeSeCo, 2006) e se concretan nos decretos curriculares das ensinanzas inicias, medias e superiores, como por exemplo: aprender a ser e facer, aprender a comunicarse e expresarse, aprender a colaborar e a relacionarse, e en resumo aprender a aprender o propio e o dos demáis.

A Lei orgánica 8/1985, do 3 de xullo, reguladora do dereito á educación, e a Lei orgánica 2/2006, do 3 de maio, de educación, establecen os principios e fins da actividade educativa.

Entre os principios da educación sinalan a transmisión dos valores que favorecen a liberdade persoal, a responsabilidade, a solidariedade, a tolerancia, a igualdade, o respecto e a xustiza, que constitúen a base da vida en común, e a participación da comunidade educativa, así como o principio do esforzo compartido que deben realizar o alumnado, as familias, o profesorado, os centros, as administracións, as institucións e a sociedade no seu conxunto como requisito necesario para asegurar unha educación de calidade con equidade.

O recentemente publicado D. $8 / 2015$, de convivencia e participación da comunidade educativa en materia de convivencia escolar recolle no seu cap. III e como posibilidade a de por en marcha porcesos de mediación, de compromiso e de equidade que servan para abordar os conflictos dende unha optica de prevención e non de sanción "pura e dura”. E así como dende os cnetros educativos poderemos empregar procesos conciliados e consensuados onde todas as partes implicadas teñan que poñer da súa parte o preciso e necesario para acadar os mellores fins: docentes, familia, alumnado...

Asemade que no memso documento figuran como obxetivos a acadar dende as comunidades educativas algúns como.

- A garantía dun ambiente educativo de respecto mutuo que faga posible o cumprimento

dos fins da educación e que permita facer efectivo o dereito e o deber de aproveitar de

forma óptima os recursos que a sociedade pon á disposición do alumnado no posto escolar. 
- A corresponsabilidade das nais e dos pais ou das titoras ou titores no mantemento da

convivencia nos centros docentes, como un dos principais deberes que lles corresponden en relación coa educación dos seus fillos ou fillas, pupilos ou pupilas.

- Avance no respecto entre todos os membros da comunidade educativa e na mellora da convivencia escolar.

- A promoción da sensibilización dos distintos sectores que interveñen na educación sobre a importancia da convivencia como parte fundamental para o desenvolvemento persoal e social do alumnado.

\section{O prodecemento conciliador}

No senso dun traballo globalizador e integrador nas diferentes comunidades educativas e dentro da búsqueda das adecuadas medidadas de mellora da convivencia estase a traballar programas ( Conéctate, Comporta-T, Convivimos...) que representan iniciativas específicas e concretas para alumnado que teñen dificultades para manter un axeitado clima de Convivencia.

A idea principal deste tipo de programas reside na prevención de comportamentos e actitudes inadecuados por parte de alumno/a e o seguemento da súa conduta durante o curso escolar dunha forma o máis sistémica sistemática e continuada posible, en estreitaa relación co seu entorno familiar.

Serán estes procesos que dan orixen a documentos e tarefas que camiñen no senso de favorecer a implicación e o compromiso do alumno ou alumna que presenta problemas de relación e disrupción habituais e da súa familia.

\section{1.- Requisitos de aplicación:}

a) Que a alumna ou o alumno responsable dalgunha das condutas prexudiciais para a convivencia recoñeza a gravidade da súa conduta, estea disposta ou disposto a reparar o dano e se comprometa a cumprir as medidas correctoras.

b) No caso de que haxa outros membros da comunidade educativa afectados pola súa conduta, que estes mostren a súa conformidade a acollerse ao dito procedemento.

A.- O procedemento conciliado non procederá nos seguintes casos:

a) Especial e notoria gravidade da conduta.

b) Cando a persoa agraviada ou, para o caso de alumnado menor de idade non emancipado/a, as persoas proxenitoras ou representantes legais deste non comuniquen a súa disposición a acollerse ao procedemento conciliado.

c) Cando a alumna autora ou o alumno autor da conduta ou as persoas proxenitoras ou representantes legais desta/e non comuniquen a súa disposición para acollerse ao procedemento conciliado.

d) Cando xa se fixese uso deste procedemento de corrección durante o mesmo curso escolar, coa mesma alumna ou co mesmo alumno, para corrixir unha conduta semellante. E non fora de especial significancia a súa aplicación.
B.- O procedemento conciliado require da instrución dun procedemento de intervención e de seguemento.

\section{2.- Desenvolvemento do procedemento conciliado}

\section{1.- Os responsables do centro:}

A dirección convocará a persoa docente designada como instrutor/a do procedemento corrector e as persoas afectadas a unha reunión, no prazo máximo dun día lectivo contado desde o remate do prazo para a comunicación da opción elixida. Preferentemente a persoa instrutora será a xefatura do Dpto. de orientación ou persoal docente do centro do equipo educativo que imparta nese curso nomeado ao caso.

- Na reunión, a persoa instrutora recordaralles ás afectadas e aos que iso supón acatar o acordo que derive deste.

- Tamén advertirá a alumna ou o alumno e, de ser o caso, as persoas ou representantes legais desta/e que as declaracións que se realicen formarán parte do expediente do procedemento no suposto de que non se alcance a conciliación.

- Posteriormente, a persoa instrutora exporá e valorará a conduta que é obxecto de corrección facendo fincapé nas consecuencias que tivo para a convivencia escolar e para os demais membros da comunidade educativa e, oídas as partes, proporá algunha das medidas de mellora para aquela conduta

- A continuación, a persoa instrutora dará a palabra á alumna ou ao alumno e ás persoas convocadas para que manifesten as súas opinións sobre a conduta que se pretende corrixir e realicen as consideracións oportunas sobre a súa corrección. A petición de desculpas por parte da alumna ou do alumno será tida en conta como circunstancia que condiciona a súa responsabilidade, á hora de determinar a medida correctora que se vaia adoptar.

-Finalmente, as persoas participantes no procedemento deberán acordar a medida correctora que consideren máis adecuada para a conduta da alumna ou do alumno e, se procede, as medidas educativas reparadoras. Deberá quedar constancia escrita da conformidade coas medidas.

2.2.- O acordo consensuado polas partes será ratificado pola persoa que exerza a dirección do centro, en cumprimento a normativa existente R.O.F do centro a ás responsabilidades sobre o mesmo.

O incumprimento por parte da alumna ou do alumno das medidas acordadas dará lugar á corrección da súa conduta mediante o procedemento común.

O procedemento conciliado finalizará unha vez obtido o acordo entre as partes. No caso de que non se logre o acordo, continuarase a corrección polo procedemento común desenvolvido conforme o previsto no artigo 53 do Decreto 8/2015.

\section{3.- Intervención dunha persoa mediadora no} procedemento conciliado.

1. No procedemento conciliado poderá actuar unha persoa mediadora na forma que se estableza nas normas de organización e funcionamento do centro. 
2. A persoa mediadora non substituirá a instrutora do procedemento, senón que colaborará con ela para lograr o achegamento entre as persoas afectadas e o seu consenso na medida correctora que se vaia aplicar.

3. As funcións que poderá desempeñar a persoa mediadora neste procedemento serán as seguintes: a) Contribuír ao proceso de conciliación. b) Axudar a que cada unha das persoas afectadas comprenda cales son os intereses, necesidades e aspiracións das outras partes para chegar ao entendemento. c) Apoiar o adecuado cumprimento do acordado no procedemento conciliado

Intentarase na medida do posible que a persoa mediadora sexa persoa que coñeza ao alumnado implicado no proceso conciliado.

\section{4.- Compromisos educativos para a convivencia:}

Pártese da consideración de que un aspecto clave para a mellora da convivencia e do rendemento nos centros escolares é a implicación das familias no proceso educativo dos seus fillos e fillas. Por elo é sempre interesante establecer e afianzar canles de implicación e participación activa entre o centro educativo e as familias.

Como definición partimos da consideración de que os compromisos de convivencia son acordos que se establecen entre o centro e as familias a fin de mellorar a integración e ao tempo o rendemento académico dun alumno o unha alumna, e favorecer a mellora do clima de convivencia no centro escolar.

O compromiso de convivencia estará indicado para o alumnado que presenta problemas de conduta ou de aceptación das normas escolares e teñen por obxecto establecer mecanismos de coordinación entre as familias e o profesorado así como doutros profesionais que atenden ao alumno ou alumna, así como colaborar na aplicación das medidas que se propoñan, tanto no tempo escolar como extraescolar, para superar esta situación.

A través de documentos como este que se inclúen no Plan de convivencia concretaranse as situacións en que poderá aplicarse esta medida, tratando sempre de potenciar o carácter preventivo da mesma e procurando que sirva para evitar situacións de alteración da convivencia ou para prever o seu agravamento.

Sempre que o considere positivo o profesorado que exerza a titoría poderá propoñer a suscripción de compromisos educativos o de convivencia, acordo co previsto no proxecto educativo do centro, e na regulamentación lexislativa ao respecto do tema. Asemade estes poderían vir propostos dende a Dirección escolar sempre coa implicación da titoría correspondente.

1. En todos os casos de condutas contrarias á convivencia, mesmo cando non haxa conciliación por non ser aceptadas as desculpas pola persoa ou persoas prexudicadas, poderase suspender a aplicación das medidas correctoras adoptadas se a alumna ou o alumno corrixida ou corrixido ou, de ser o caso, as persoas proxenitoras ou representantes legais desta/e asinan un compromiso educativo para a convivencia.

2. Nun compromiso educativo para a convivencia deberá figurar de forma clara e detallada a que se compromete a alumna ou o alumno ou, de ser o caso, as persoas proxenitoras ou representantes legais desta/e, e as actuacións de formación para a convivencia, prevención e de modificación de condutas, que aquelas/es se comprometen a levar a cabo, persoalmente ou mediante a intervención de institucións, centros docentes ou persoas adecuadas. Igualmente, deberán constar os mecanismos de comunicación e coordinación co centro.

3. A falta de cumprimento dos compromisos adquiridos por parte da alumna ou do alumno ou, de ser o caso, das persoas proxenitoras ou representantes legais desta/e determinará a aplicación inmediata das medidas correctoras suspendidas.

4. O centro educativo poderá concretar nas súas normas de organización e funcionamento o procedemento para acordar co alumnado corrixido e, de ser o caso, coas persoas proxenitoras ou representantes legais destas/es compromisos educativos para a convivencia segundo o previsto neste documento.

Poderanse distinguirse entre:

A.- Compromisos de prevención e colaboración, que fomenten a participación e a cooperación:

- Para asumir principios de colaboración entre a familia e o centro.

- Para poñer en marcha programas de HH.SS como elemento formativo dos intervintes.

- Para asumir o cumprimento dunha obrigación determinada.

- Para focalizar esforzos en torno a un logro/s.

- Para establecer elementos de verificación de avance.

- Para asegurar o cumprimento dun pacto establecido entre a familia e o centro.

- Para anticiparnos a posibles problemas.

B.- Compromisos de intervención paliativa:

- Ante condutas non desexables. E fundamentalmente as recollidas no propio Regulamento de Organización e Funcionamento.

- Ante a falta de coidados e atención por parte das familias.

- Para acordar cambios de actitudes.

- Para establecer medidas alternativas a unha sanción.

- Como consecuencia de un proceso de mediación inicial.

\subsection{Procedemento para a suscripción dos compromisos educativos e de convivencia.}

O procedimento para suscribir compromisos educativos e de convivencia coas familias debe quedar establecido no Proxecto Educativo do centro, a través deste documento. Asemade, debe recollerse o procedemento para realizar o seguimento por parte da Comisión de Convivencia (D. 8/2015) e do Consello Escolar do cumprimento e efectividade das medidas incluídas nos mesmos.

Os compromisos educativos e de convivencia adoptaranse por escrito, establecendo as medidas concretas, as datas os cauces de avaliación da efectividade das mesmas. Tamén debe quedar constancia escrita da posibilidade de modificar o compromiso no caso de incumprimento por algunha das partes ou si las medidas adoptadas non dan o resultado esperado. 
Unha vez suscrito o compromiso de convivencia, o titor ou titora dará traslado do mesmo á dirección do centro, que o comunicará á comisión de convivencia e ao Consello Escolar.

O Consello Escolar, a través da comisión de convivencia, garantirá a efectividade dos compromisos de convivencia que se suscriban no centro e proporá as medidas e iniciativas a adoptar en caso de incumprimento.

\subsection{Mecanismos de seguemento e avaliación}

No propio Plan de Convivencia recollerá a posible duración dos Compromisos de Convivencia, así como a periodicidade no intercambio de información ás familias e a Comisión de Convivencia do centro.

A duración dos Compromisos establecerase en función dos obxectivos a conseguir e do perfil e das necesidades de cada alumno o alumna con cuia familia se vaian a suscribir.

O titor ou titora coordinará igualmente esta medida con outras contempladas no Plan de Convivencia en colaboración e co asesoramenteo do Dpto de orientación.

O Plan de Convivencia incluirá o procedimiento para o seguemento e avaliación por parte da Comisión de Convivencia, quen garantizará a efectividade e imparcialidade dos Compromisos e proporá a adopción de medidas e iniciativas no caso de incumprimento, entre as que se poderá contemplar a anulación do mesmo.

Si se incumprira ese Compromiso de Convivencia, o titor/a deberá poñelo en coñecemento do equipo educativo e do equipo directivo para que dé traslado dos feitos á Comisión de Convivencia, que proporá as medidas e iniciativas a adoptar en función do previsto no Plan de Convivencia a tal efecto.

MODELO DE POSTA EN MARCHA E SEGUEMENTO

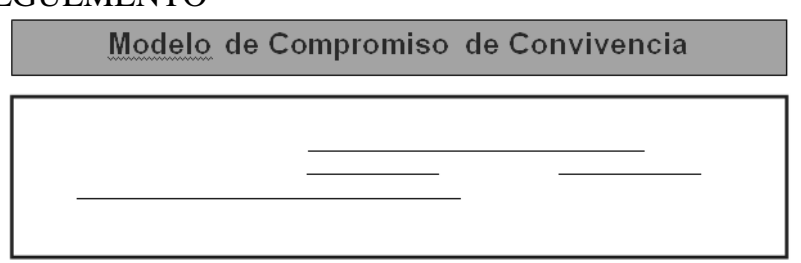

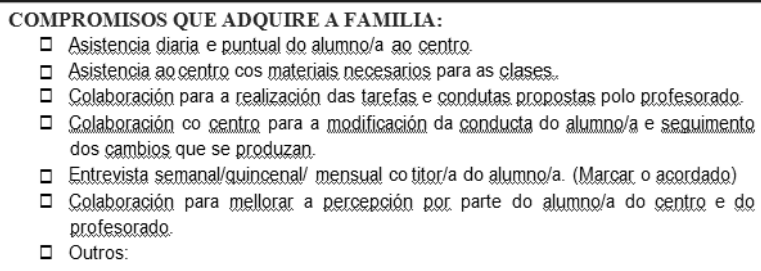

\footnotetext{
COMPROMISOS QUE ADQUIRE O CENTRO:

$\square$ Control diario e información inmediata aos representantes legais sobre a possible ausencia do alumno/a

口 Seguimento dos cambios que se produzan na súa actitude e información á familia.

$\checkmark$ Aplicación de medidas preventivas para mellorar a súa actitude (aula de tempo fora mediación, etc.).

$\square$ Entrevista entre o representante legal do alumno e o titor/a coa periodicidade establecida. Póderase contar coa presenza de director/a do Dpto de Orientación e/ou a xefatura de estudos.

$\square$ Outros:
}

Figura 1. Modelo de Compromiso de Convivencia
Ficha para o centro
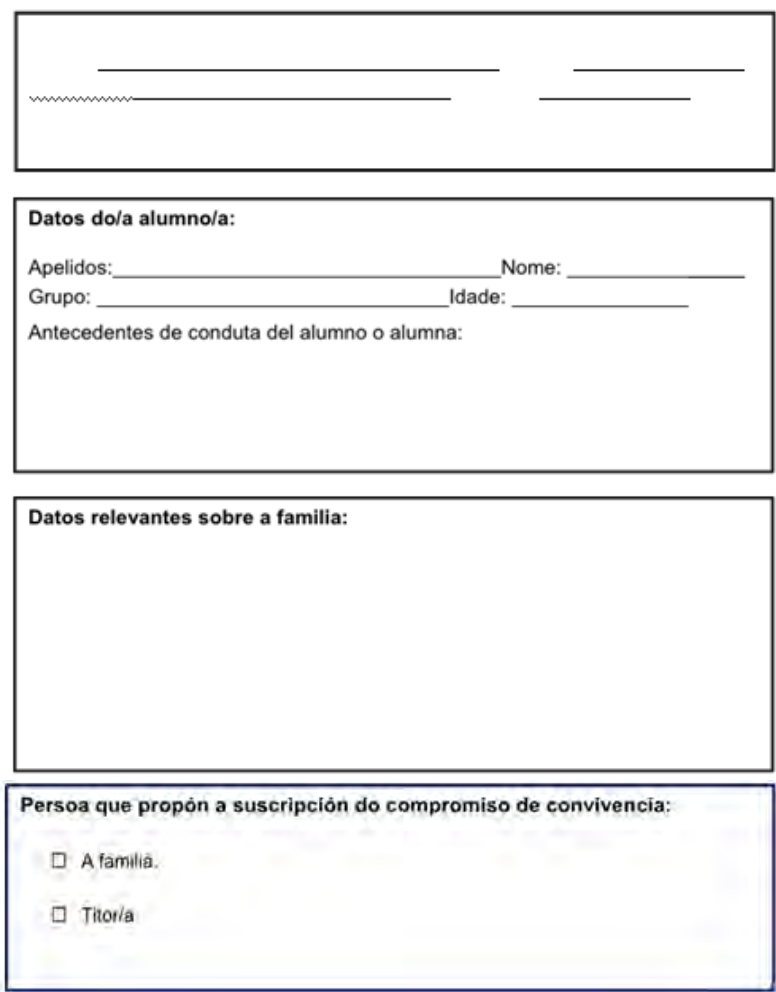

Figura 2. Ficha para o centro

\section{Seguemento do Compromiso}

\begin{tabular}{|l|}
\hline DURACION DO COMPROMISO: \\
\hline PERIODICIDADE DA INFORMACION A FAMILIA: \\
\hline DATAS DE REVISION E AVALIACION: \\
\hline COMUNICACION A COMISION DE CONVIVENCIA: \\
\hline ACTUACIONS NO CASO DE INCUMPRIMENTO DO COMPROMISO: \\
\hline
\end{tabular}




\begin{tabular}{|l|l|}
\hline \multicolumn{2}{|l|}{$\begin{array}{l}\text { DATOS SOBRE A EVOLUCIÓN DO ALUMNO/A } \\
\text { (Valoración global dos obxectivos acadados e non acadados) }\end{array}$} \\
\hline \multicolumn{2}{|l|}{ Realiza as tarefas que se lle encomendan } \\
\hline Interactúa de forma axeitada na clase & \\
\hline Amosa unha actitude respetuosa: & \\
\hline Amosa unha actitude reflexiva e cooperativa: & \\
\hline Amosa indicios de mellora: & \\
\hline Establece compromisos: & \\
\hline Non Ile puxeron partes: & \\
\hline Non foi expulsado de clase: & \\
\hline Non expulsado do centro: & \\
\hline Outros datos de intres: & \\
\hline VALORACION GLOBAL: & \\
\hline
\end{tabular}

Figura 3. Seguemento de compromiso

\section{Referencias Bibliográficas}

Ararteko. Convivencia y conflictos en los centros educativos. Bilbao. Ararteko 2006.

Decreto 8/2015 del 8 de enero, por el que se desenvuelve la Lei 472011, del 30 de junio, de convivencia y participación de la comunidad educativa en materia de convivencia escolar (DOGA del martes 27 de enero).

Defensor del pueblo. Informe sobre violencia escolar. Madrid. Defensor del Pueblo. 2010.

Delors,J et al. La educación encierra un tesoro. Informe UNESCO de la Comisión Internacional sobre la Educación para el siglo XXI. Madrid. Santillana-Unesco
Informe DeSeCo. Las competencials clave para el bienestar personal, económico y social ( $1^{\mathrm{a}}$ ed. en español, 2006).

Ley Orgánica 2/2006, de 3 de mayo, de educación. (B.O.E de 4 de mayo de 2006).

Ley 4/2011, do 30 de xuño, de convivencia e participación da comunidade educativa (DOGA del viernes 15 de julio de 2011).

Ley orgánica 8/2013, de 9 de diciembre, para la mejora de la calidad educativa (B.O.E de 10 de decembro de 2013).

Proyecto atlántida. Convivecnia democrática y disciplina escolar, www.proyecto-atlántida.org

Segura, M. Ser persona y relacionarse. Habilidades cognitivas, sociales y crecimiento moral.Madrid. Narcea. 2005.

Veiga, E; Rodriguez, E. (2008). Desarrollo integral de la convivencia en el marco educativo. Una nueva perspectiva: Del observatorio Autonómico al Observatorio Escolar. Revista galego-Portuguesa de psicoloxía e Educación. UDC. A Coruña.

Zaitegi, N. El equipo directivo y las gestión de la convivencia en el centro. Revista Perspectiva. Junta de Andalucía (2006)

Zaitegi, N. La educación en y para la convivencia positiva en España. Revista Iberoamericana sobre Calidad, Eficacia y Cambio en Educación (2010) - Volumen 8, Número 2.

Proyecto DeSeCo en Internet www.OECD.org/edu/statistics/deseco www.deseco.admin.ch 